\title{
A Technique for Estimating Small Mammal Population Densities Using a Grid and Assessment Lines
}

\author{
David M. SWIFT \& R. Kirk STEINHORST
}

\begin{abstract}
Swift D. M. \& Steinhorst R. K., 1976: A technique for estimating small mammal population densities using a grid and assessment lines. Acta theriol., 21, 32: $471-480$ [With 2 Tables \& 1 Fig.].

A technique, for estimating densities of small mammal populations utilizing live trapping on a grid and assessment lines is presented. Information from the assessment lines permits estimation of the area of effect of the grid and of the proportion of the population marked within that area. These, in conjunction with the number of animals known to have marked on the grid, yield a Lincoln Index-type of estimate of population density. Results of a field validation study of the technique are presented.

Nat. Res. Ecol. Lab., Colorado State Univ., Fort Collins, Col. 80523
\end{abstract} USA].

\section{INTRODUCTION}

A wide variety of techniques exist for estimating population size in small mammals. Most techniques, however, do not yield an estimate of the area associated with the population; and since density is number per unit area, they do not yield density estimates.

S a r r a z in \& Bider (1973) provide a technique combining removal trapping with an estimate of the resulting decreased activity of the population that yields a density estimate. The technique of estimating population activity by checking fine sand transects for tracks every two hours may be too laborious for many applications, however.

Dice (1938) suggested that the area actually sampled by a grid of traps could be estimated by adding a strip around the grid equal in width to one-half the width of the home range of the species being censused. This is a good estimate of area sampled only if the grid is a neutral factor in the animals' environment. If the animals are attracted or repelled by the grid, the actual area sampled may not be directly related to size of their home ranges. Additionally, the estimation of home range size is a substantial problem in itself.

Another approach to estimating density has been to combine removal trapping with subsequent trapping on assessment lines to evaluate the area of effect of the original trapping. $\mathrm{S} \mathrm{mith} \mathrm{et} \mathrm{al.} \mathrm{(1971)} \mathrm{combined}$

[471] 
assessment lines with grid trapping while $\mathrm{Ka}$ afman et al. (1971) trapped first on census lines and subsequently on assessment lines crossing them. In both cases, regression equations relating accumulated captures to distance along the assessment lines within the affected area are used in conjunction with similar regression equations developed from data taken outside the affected area to estimate the proportion of the population removed from that area. No objective method for locating the edge of the area of effect is provided however and that determination will affect the final density estimates. In addition, Gentry, $\mathrm{Smith} \&$ Chelton (1971) have shown that if reinvasion occurs after the original removal trapping, subsequent assessment line trapping may not be able to elucidate an area of effect at all.

The method presented here requires no subjective judgments regarding the size of the area of effect and is designed to be employed with capture-mark-release data so that reinvasion problems are circumvented. This estimator was used in 1972 to estimate small mammal densities at field sites of the US/IBP Grassland Biome.

\section{CONCEPTUAL FRAMEWORK}

The problem of defining the area associated with a population estimate arises from the fact that when animals are trapped on a grid network, the area of effect of the grid is not known. The area of effect is likely to be somewhat larger than the grid, so that the grid exhibits a positive edge effect. A simple illustration will indicate how an edge effect might be generated and how it might be measured. With respect to the grid, there are three classes of animals; they are:

1. Those whose activity ranges are normally entirely within the grid.

2. Those whose activity ranges are normally partly within and partly without the grid.

3. Those whose activity ranges are normally entirely without the grid. Animals of Class 1 are the most likely to be captured, but the probability of capturing Class 2 animals is still fairly high. If Class 2 animals are captured, the grid is sampling an area larger than itself since those animals spend at least part of their time off the grid. Additionally, animals of Class 3 may be captured if the grid is a sufficiently attractive force to cause animals to make forays from their normal activity ranges. The probability of capturing an animal of Class 3 is lower than that for an animal of Class 1 or Class 2, however.

In fact, animals do not relate spatially to the grid in terms of three discrete classes. It is more satisfying to think in terms of a continuum of such spatial relationships, from animals whose activity ranges are 
entirely within the grid and whose probability of capture is the highest, through those whose activity ranges are decreasingly within the grid to those whose activity ranges are so far from the grid that their probability of capture is vanishingly small.

If the probability of capture decreases with increasing distance from the grid, one would expect that, following the marking and releasing of animals on a grid, a similar pattern would exist in the proportion of marked animals on and around the grid. That is, the proportion of marked to total animals should be highest on the grid and decrease with increasing distance from the grid until a point is reached beyond which this proportion is zero. This point defines the area of grid effect.

If the relationship between proportion marked and distance can be quantified and the number of animals marked on the grid $\left(N_{0}\right)$ is known, then a density estimate is available. All that is needed in addition to $N_{0}$ is the area of grid effect $\left(A^{\prime}\right)$ and the proportion marked within that area $\left(P_{m}\right)$. Both $A^{\prime}$ and $P_{m}$ can be obtained from the relationship between proportion marked and distance. Having all three, the total number of animals is $N_{0} / P_{m}$ and density is $\left(N_{0} / P_{m}\right) / A^{\prime}$.

In practice the density estimate may be obtained by:

1. Marking and releasing animals on a grid of traps,

2. Retrapping in an area large enough to include the grid and its area of effect,

3. Calculating the ratio of marked to total animals $(M / T)$ at various distances from the grid center (a measure of proportion of animals marked at those distances),

4. Quantifying the relationship between distance and $M / T$,

5. Solving for $A^{\prime}$ and $P_{m}$, and

6. Solving for density.

\section{ASSUMPTIONS}

Since this is a modification of the Lincoln Index model, the usual assumptions must be met. Two additional assumptions are necessary as well, due to the areal consideration. The assumptions are:

1. There exists a well-defined population of animals, the size of which does not change during sampling.

2. A known number of these animals is marked.

3. A known number of subsequent observations of the population exists including a known number of observations of marked animals.

4. The average probability of observing a marked animal is equal to the average probability of observing an unmarked animal. 
5. If the process of marking has caused any spatial redistribution of the population, it returns to its premarking configuration before the subsequent observation period begins.

6. Within the area of grid effect, population density does not vary with distance from the grid center.

Assumptions 1 through 4 are taken from Overton \& Davis (1969) and must be met for the usual reasons. Assumption 5 must be met if the ratio of captures of marked animals to total captures $(M / T)$ at any point is to be a good measure of proportion of animals marked at that point. Assumption 6 must be met if the average of the observed proportions within the area of effect is to be a good measure of the proportion marked within the area.

\section{GRASSLAND BIOME FIELD METHOD}

The field methods employed in the Grassland Biome study in 1972 consisted of 5 days of capture-mark-release trapping on a grid followed by 5 days of captureobserve-release trapping on assessment lines.

The grid contained 144 live-trap stations spaced 15 meters apart in a $12 \times 12$ arrangement. Traps were baited and set in the evening, checked, and closed in the early morning. Normally, two traps were set per station, except at sites known to have low small mammal populations where only one trap was set.

The assessment line design was one proposed by S mith, B e y e r \& G e n try (1970). Eight assessment lines were established for each grid (Fig. 1). Four lines bisected the corner angles of the grid and extended $37.5 \mathrm{~m}$ into the grid. The other four lines were perpendicular bisectors of the grid sides and extended $67.5 \mathrm{~m}$ into the grid. All eight lines extended out $177.5 \mathrm{~m}$ from the edge of the grid. Intertrap interval was $15 \mathrm{~m}$. Diagonal lines thus had 15 stations each and perpendicular lines had 17 stations each, a total of 128 stations. Either one or two traps were set per station, as on the grid. Again trapping was nocturnal.

\section{GRASSLAND BIOME ANALYTICAL METHODS}

The data collected using the described field procedures were analyzed as follows, for each species caught.

The grid trapping data were tabulated to determine the number of individuals marked $\left(N_{0}\right)$. In analyzing the assessment line data, eaci trapped animal was classified as marked or unmarked depending upon whether or not it had been captured during the preceding grid trapping session. The distance from the center of the grid to the assessment line trap in which the animal was caught was calculated. After the assessment line data had been so cataloged, the ratio of "marked" captures to total captures $(M / T)$ was calculated for each distance from the grid center at which trap stations occurred.

The distances from the grid center were converted to the areas they enclosed $(A)$ and a regression relationship between $M / T$ and $A$ was 
developed. The conversion from distance to area permitted us to find the average proportion marked, directly, in terms of area rather than distance. A linear regression was used so the form of the relationship was $M / T=a+b A$. By setting $M / T=0$ in this relationship and solving for $A$, we found the area $\left(A^{\prime}\right)$ beyond which the proportion of marked animals was zero - or beyond which the grid had no effect.

We then knew that $N_{0}$ marked animals were within the area $A^{\prime}$. To find the total population within $A^{\prime}$, the proportion of the total population that was marked had to be found. The average value of $M / T$ within the area $A^{\prime}$ can be found by integration of the regression equation. Since $M / T$ is a measure of the proportion of marked animals in the population, the average value of $M / T \overline{(M / T)}$ could be set equal to the proportion of marked animals $\left(P_{m}\right)$ in the area $A^{\prime}$. That is:

$$
P_{m}=\overline{M / T}=\frac{1}{A^{\prime}} \int_{0}^{A^{\prime}}(a+b A) d A .
$$

Density was then calculated as

$$
\left(N_{0} / P_{m}\right) / A^{\prime} .
$$

In practice we discovered that a regression between $M / T$ and area, employing observations of $M / T$ and area at each possible distance from the grid center, was not satisfactory due to the generally low population densities encountered. So few captures were recorded at each distance on the assessment line that most estimates of $M / T$ were being made on the basis of three or fewer captures and thus were not reliable.

To circumvent this problem, data from the assessment lines were grouped into capture bands $45 \mathrm{~m}$ in width. Captures at all stations within each band were used to calculate a single value of $M / T$ for that band. Any capture band in which no animals were captured was eliminated from the regression because $M / T$ for that band would be $0.0 / 0.0$, which is undefined. In cases where the outermost two or more bands all yielded $M / T$ values of zero (all animals trapped were unmarked), only the innermost such band was included in the regression. This band is useful in defining the area of effect, but zero values at greater distances add no information and can serve only to bias the regression. Thus, the regression may be based on fewer than the six observations that one would expect from such a grouping of the data.

The distance from the grid center to the center of each band was used to calculate the area associated with that band and its value of $M / T$. The regression was performed on these grouped data.

The program written to make these calculations also generated a 
standard Lincoln Index estimate of the population. For this purpose, the marking period was, as before, the grid trapping period; but retrap information was taken only from those assessment line traps lying within the grid boundaries. A density estimate was calculated from the result assuming that the area sampled was equal to the grid area. Bringing the two density estimates into agreement then yielded a "boundary strip" around the grid which had to be added to the grid area in order to adjust the Lincoln density to the regression density.

This was done for two reasons. First, we wished to see what order of difference existed between the two estimates. Second, it was felt that the size of the boundary strip should be indicative of the normal range of movement of the various species trapped. A wide ranging species should produce a wider boundary strip than a sedentary one.

The results obtained from applying this method to the Grassland Biome data were generally encouraging. Density estimates which appeared reasonable were produced in most cases in which 10 or more animals were marked on the grid. Interspecific variation in the calculated size of the boundary strip reflected our understanding of the mobility of the species involved.

\section{FIELD VALIDATION STUDY}

Although the estimator performed fairly well on the Grassland Biome data, these data could not be used for validation of the technique since, in no case, was the true density known. It was felt that, for validation purposes, a field study in an area of known population density should be undertaken. We were fortunate to have available to us for this purpose, a portion of the facilities of the Rock Valley Ecology Study Area of the Energy Research Development Agency's Nevada Test Site in southern Nevada.

Field work was conducted from 20 August to 29 August 1973 in a 9-ha circular enclosure defined by a rodent-proof fence. This enclosure can be censused accurately by saturation trapping ( $\mathrm{French}$ et al., 1974). This is done on a regular basis. When census trapping is performed, any unmarked animal captured is marked, either by ear tags or a system of toe amputation. Marked animals captured are noted and released. The most recent census trapping had been performed on 7, 8, and 9 August 1973 by personnel from the Laboratory of Nuclear Medicine and Radiation Biology at the University of California at Los Angeles. The results of this census, as modified by our trapping experience, were used to determine the true densities of the species involved. 
Two Hetermyid species, Dipodomys microps and Perognathus formosus, constituted the bulk of the small mammal population within the enclosure. Two other species, Perognathus longimembris and Onychomys torridus were also present, but were captured by us in such low numbers their densities could not be estimated. The 7-9 August census showed six $P$. longimembris and two $O$. torridus within the 9-ha enclosure. Populations of the two major species were below normal levels (B. G. M a z a, pers. comm.).

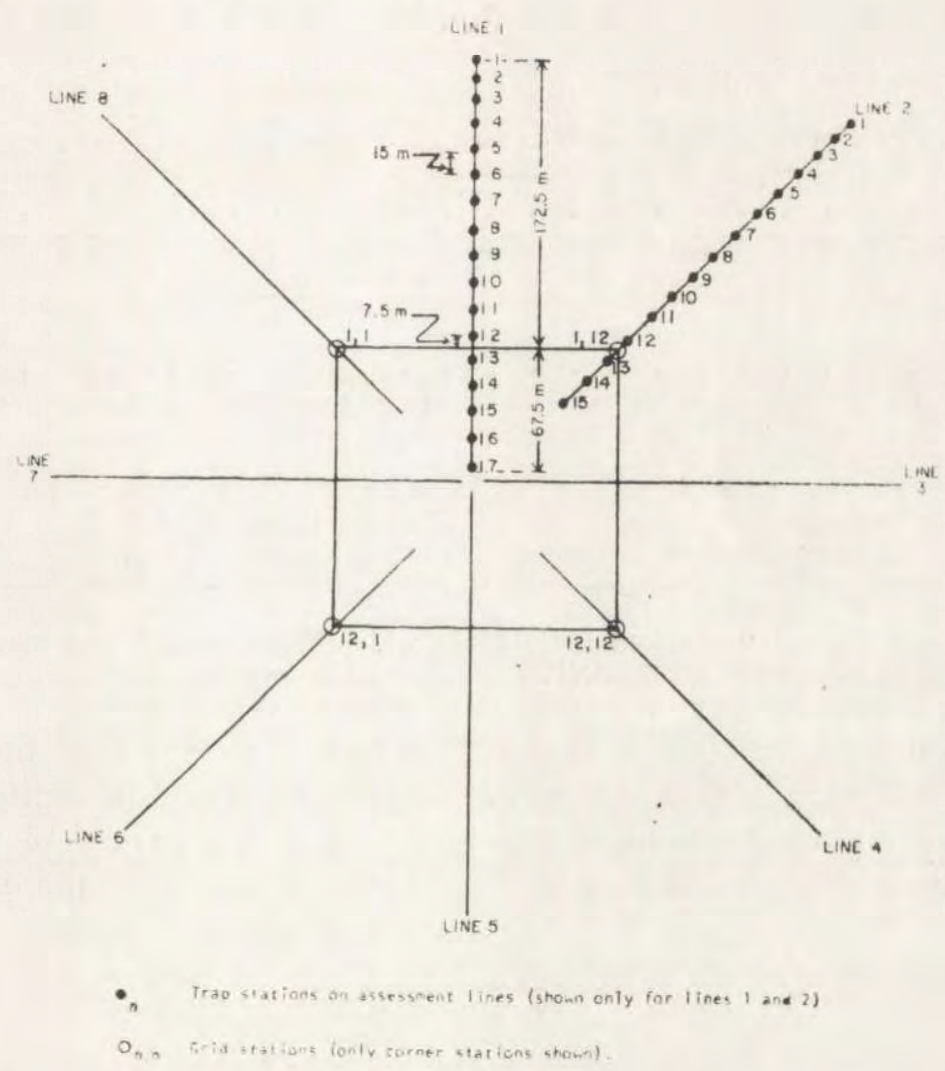

Fig. 1. Grassland Biome small mammal trap grid and assessment lines (not drawn to scale).

The 9-ha enclosure was too small to permit use of the field design used in the Grassland Biome studies so a reduced version of the same pattern was used. A $7 \times 7$ grid of traps at $15-\mathrm{m}$ intervals, with its center at the enclosure center, was established for the marking phase. This reduced grid $(0.81 \mathrm{ha})$ was used to insure that the area of grid effect would be less than the entire enclosure. Eight assessment lines were 
established for the recapture phase. These were laid out as in Fig. 1, but were shortened to fit within the enclosure. A $10-\mathrm{m}$ intertrap distance was used on the lines so that the number of assessment line traps would approximate the number in the original field design. The 9-ha enclosure has a $15-\mathrm{m}$ radius exclosure at its center. This eliminated the center grid trap and permitted 16 traps per assessment line. Diagonal lines had 5 traps within the grid and 11 traps without; perpedicular lines had 3 within and 13 without.

Sherman-type live traps with heat shields, baited with rolled oats, were used, with one trap per station. The grid was trapped for five successive nights, followed immediately by five successive nights of trapping on the assessment lines.

\section{Table 1}

Comparison of actual densities with densities estimated from two techniques for two species of desert rodents.

\begin{tabular}{lccccc}
\hline Species & $\begin{array}{c}\text { Actual } \\
\text { no. in } \\
9 \text { ha }^{1}\end{array}$ & $\begin{array}{c}\text { Actual } \\
\text { density } \\
\text { (no.ha) }\end{array}$ & $\begin{array}{c}\text { Regression } \\
\text { density } \\
\text { (no./ha) }\end{array}$ & $\begin{array}{c}\text { Lincoln } \\
\text { density } \\
\text { (no./ha) }\end{array}$ & $\begin{array}{c}\text { Width of } \\
\text { border strip } \\
\text { to adjust } \\
\text { Lincoln } \\
\text { density }(m)\end{array}$ \\
\hline $\begin{array}{l}\text { Perognathus formosus } \\
\text { Dipodomys microps }\end{array}$ & 34 & 3.78 & 2.35 & 8.64 & 29.0 \\
\hline
\end{tabular}

1 Number of individuals captured during the 7-9 August census, plus the number of previously unmarked individuals which were caught and marked from $20-29$ August, minus known mortality.

The resulting data were analyzed as before except that the assessment line data were grouped into $30-\mathrm{m}$ rather than $45-\mathrm{m}$ capture bands as a result of having reduced the intertrap interval from 15 to $10 \mathrm{~m}$. Eight capture bands resulted from this grouping. Only those animals which we had captured on our grid were considered "marked" for the purpose of our analysis.

\section{RESULTS}

Our method yielded density estimates for two species, $P$. formosus and D. microps. Comparison of those estimates with the actual densities and density estimates using the direct Lincoln estimator are found in Table 1, along with our estimate of the border strip necessary to adjust the Lincoln estimate to the regression estimate. Characteristics of the regressions and of the regression estimator are given in Table 2.

\section{DISCUSSION}

Although population densities at the field validation site were too 
low to provide a definitive test of the method, it appears promising. The density estimates were close to the true densities and much more accurate than density estimates ignoring the possibility of an area of grid effect larger than the grid itself. The regression estimate was $38 \%$ low for $P$. formosus and $7 \%$ low for $D$. microps, while the Lincoln estimates were 129 and $302 \%$ high for the two species, respectively.

With both the validation data and the Grassland Biome data, the regression technique consistently yielded density estimates that were only $1 / 2$ to $1 / 4$ the density estimates obtained by any method ignoring the area of grid effect. It is clear that with some species at least, this area may be quite large and that ignoring its existence in estimating population densities will lead to considerable bias.

Table 2

Characteristics of regression and regression estimator for two species of desert rodents. No. indicates number of observations for regression.

\begin{tabular}{lccccccc}
\hline Species & No. & $R^{2}$ & $\begin{array}{c}\text { No. } \\
\text { caught } \\
\text { on grid } \\
\left(N_{0}\right)\end{array}$ & $\begin{array}{c}\text { Area of } \\
\text { grid } \\
\text { (ha) }\left(A^{\prime}\right)\end{array}$ & $\begin{array}{c}\text { Proportion } \\
\text { marked } \\
\text { in } A^{\prime} \\
(\bar{M})\end{array}$ & $\begin{array}{c}\text { Density } \\
(\text { no.ha) }\end{array}$ & $\begin{array}{c}\text { Distance } \\
\text { from edge } \\
\text { of grid } \\
\text { to edge } \\
\text { of } A^{\prime}(\mathrm{m})\end{array}$ \\
\hline P. formosus & 6 & 0.775 & 7 & 5.90 & 0.506 & 2.35 & 60.0 \\
D. microps & 7 & 0.673 & 9 & 7.30 & 0.412 & 2.99 & 73.0 \\
\hline
\end{tabular}

The current technique does not work well in situations in which densities are very low or on species whose range of movement is large compared to the scale of the field design. These problems are not unique to this estimator, however.

The field design used in this study may not be optimal for use in areas where population densities are low. A modified design incorporating more assessment lines might eliminate the need to group data into capture bands to obtain reliable estimates of $M / T$ at different distances from the grid. Any design which provides a central marking locality and a means of estimating $M / T$ at various distances from that center could be employed.

Acknowledgments: The authors gratefully acknowledge Dr. Norman R. French for his advice and encouragement, Dr. William Grant for his advice and for performance of the validation field work, $\mathrm{Mr}$. Bernardo $\mathrm{M} \mathrm{a} \mathrm{za}$ for access to his data and for his gracious logistical support at the Nevada Test Site, and the Energy Research Development Agency for the use of their facilities there. This paper reports on work supported in part by National Science Foundation Grants GB-31862X, GB-31862X2, GB-41233X, and BMS73-02027 A02 to the Grassland Biome, U.S. International Biological Program, for "Analysis of Structure, Function, and Utilization of Grassland Ecosystems «. 


\section{REFERENCES}

1. Dice L. R., 1938: Some census methods for mammals. J. Wildl. Manage., 2: $119-130$.

2. French N. R., Maza B. G., Hill H. O., Aschwanden A. P. \& Kazz H. W., 1974: A population study of irradiated desert rodents. Ecol. Monogr., 44: $45-72$.

3. Gentry J. B., Smith M. H. \& Chelton J. G., 1971: An elevation of the octagon census method for estimating small mammal populations. Acta theriol., 16: $149-159$.

4. Ka $\mathrm{ufm}_{\mathrm{m}}$ D. W., Smith G. C., J ones R. M., Gentry J. B. \& Smith M. H., 1971: Use of assessment lines to estimate density of small mammals. Acta theriol., 16: 127-147.

5. Overton Q. S. \& Davis D. E., 1969: Estimating the numbers of animals in wildlife populations, [In: "Wildlife management techniques, 3rd ed." ed. R. H. Giles, Jr.]. The Wildlife Society: 403-455. Washington, D. C.

6. Sarrazin J. P. R. \& Bider J. R., 1973: Activity, a neglected parameter in population estimates - The development of a new technique. J. Mammal., 54: $369-382$.

7. Smith M. H., Beyers R. J. \& Gentry J. B., 1970: Reliable density estimates for small mammal species. Research proposal from the Savannah River Ecology Laboratory of the University of Georgia: 1-126. Athens, Georgia.

8. Smith M. H., Blessing R., Chelton J. G., Gentry J. B., Golley F. B. \& McGinnis J. T., 1971: Determining density for small mammal populations using a grid and assessment line. Acta theriol., 16: 105-125.

Accepted, December 15, 1975.

David M. SWIFT i R. Kirk STEINHORST

\section{METODA OKRESLANIA ZAGESZCZENIA W POPULACJACH MAEYCH SSAKOW PRZY UŻYCIU DZIAEKI ODEOWNEJ I TRANSEKTOW}

\section{Streszczenie}

Przedstawiono metodę określania zagęszczenia w populacjach drobnych ssaków przy użyciu żywołówek na działkach odłownych i transektach. Dane $z$ transektów pozwalają ustalić zasięg oddziaływania działki oraz dostarczają informacji o populacji oznaczonej na powierzchni. 